University of Nebraska - Lincoln

DigitalCommons@University of Nebraska - Lincoln

Publications from USDA-ARS / UNL Faculty

U.S. Department of Agriculture: Agricultural

Research Service, Lincoln, Nebraska

2012

Switchgrass PviCAD1: Understanding Residues Important for Substrate Preferences and Activity

\author{
Aaron J. Saathoff \\ USDA-ARS Grain, Forage, asaathoff2@unl.edu \\ Mark S. Hargrove \\ lowa State University, msh@iastate.edu \\ Eric J. Haas \\ Creighton University, EricHaas@creighton.edu \\ Christian M. Tobias \\ USDA-ARS Genomics and Gene Discovery Unit, christian.tobias@ars.usda.gov \\ Paul Twigg \\ University of Nebraska at Kearney, twiggp@unk.edu \\ See next page for additional authors
}

Follow this and additional works at: https://digitalcommons.unl.edu/usdaarsfacpub

Saathoff, Aaron J.; Hargrove, Mark S.; Haas, Eric J.; Tobias, Christian M.; Twigg, Paul; Sattler, Scott; and Sarath, Gautam, "Switchgrass PviCAD1: Understanding Residues Important for Substrate Preferences and Activity" (2012). Publications from USDA-ARS / UNL Faculty. 1294.

https://digitalcommons.unl.edu/usdaarsfacpub/1294

This Article is brought to you for free and open access by the U.S. Department of Agriculture: Agricultural Research Service, Lincoln, Nebraska at DigitalCommons@University of Nebraska - Lincoln. It has been accepted for inclusion in Publications from USDA-ARS / UNL Faculty by an authorized administrator of DigitalCommons@University of Nebraska - Lincoln. 


\section{Authors}

Aaron J. Saathoff, Mark S. Hargrove, Eric J. Haas, Christian M. Tobias, Paul Twigg, Scott Sattler, and Gautam Sarath 


\title{
Switchgrass PviCAD1: Understanding Residues Important for Substrate Preferences and Activity
}

\author{
Aaron J. Saathoff • Mark S. Hargrove • Eric J. Haas • \\ Christian M. Tobias • Paul Twigg • Scott Sattler • \\ Gautam Sarath
}

Received: 20 January 2012 / Accepted: 9 August 2012 /

Published online: 23 August 2012

(C) Springer Science+Business Media, LLC (outside the USA) 2012

This article is a U.S. government work, and is not subject to copyright in the United States.

\begin{abstract}
Cinnamyl alcohol dehydrogenase (CAD) catalyzes the final step in monolignol biosynthesis. Although plants contain numerous genes coding for CADs, only one or two CADs appear to have a primary physiological role in lignin biosynthesis. Much of this distinction appears to reside in a few key residues that permit reasonable catalytic rates on monolignal substrates. Here, several mutant proteins were generated using switchgrass wild type (WT) PviCAD1 as a template to understand the role of some of these key residues, including a proton shuttling HL duo in the active site. Mutated proteins displayed lowered or limited activity on cinnamylaldehydes and exhibited altered kinetic properties compared to the WT enzyme, suggesting that key residues important for efficient catalysis had been identified. We have also shown that a sorghum ortholog containing EW, instead of HL in its active site, displayed negligible activity against monolignals. These results indicate that lignifying CADs require a specific set of key residues for efficient activity against monolignals.
\end{abstract}

Keywords Switchgrass $\cdot$ Cinnamyl alcohol dehydrogenase $\cdot$ Lignin $\cdot$ Protein mutagenesis

\author{
A. J. Saathoff $\cdot$ S. Sattler $\cdot$ G. Sarath $(\bowtie)$ \\ USDA-ARS Grain, Forage, and Bioenergy Research Unit, University of Nebraska, 137 Keim Hall, \\ Lincoln, NE 68583-0937, USA \\ e-mail: Gautam.Sarath@ars.usda.gov \\ M. S. Hargrove \\ Department of Biochemistry, Biophysics \& Molecular Biology, Iowa State University, \\ 4114 Molecular Biology Building, Ames, IA 50011, USA \\ E. J. Haas \\ Department of Chemistry, Creighton University, 2500 California Plaza, Omaha, NE 68178, USA \\ C. M. Tobias \\ USDA-ARS Genomics and Gene Discovery Unit, 800 Buchanan St., Albany, CA 94710, USA \\ P. Twigg \\ Department of Biology, University of Nebraska-Kearney, Kearney, NE 68849, USA
}




\section{Introduction}

Terrestrial land plants have been estimated to assimilate about $56 \mathrm{Gt}$ of carbon annually [1]. Much of this carbon is used in the synthesis of cellulose [2, 3], hemicellulose [4], and lignin [5], which make up the three main components of plant cell walls and are the most abundant polymers on earth. Because of their abundance, these three polymers offer attractive targets for producing renewable fuels, power, and chemicals. However, the complex nature in which these polymers are interconnected in plant cell walls has presented formidable technical challenges in developing cost-effective and environmentally benign conversion technologies based on a biochemical platform. Therefore, understanding how plants control and synthesize their cell wall components, especially lignins, is important for targeting efforts towards developing perennial plants, such as switchgrass (Panicum virgatum L.), which are more amenable to conversion processes $[6,7]$.

Lignin is a complex heteropolymer consisting primarily of three main phenylpropanoid subunits: $p$-hydroxyphenyl (H-lignin), guaiacyl (G-lignin), and syringyl (S-lignin) units which are derived from their respective alcohols [8, 9]. Lignin has also been found to contain additional constituents such as acylated and aldehyde units and, in grasses, ferulate [5]. Compared to dicots, grasses have substantially more lignin in their secondary cell walls [10]. The various types of chemical bonds found in lignin have made compositional and structural analysis difficult [11].

Current research has implicated approximately ten enzymes in monolignol biosynthesis $[5,8,12]$. A key enzyme involved in the later steps of lignin biosynthesis is cinnamyl alcohol dehydrogenase (CAD), which catalyzes the reduction of $p$-hydroxycinnamaldehydes to their corresponding alcohols (Fig. 1). Cinnamylalcohols are the primary monomers incorporated into the lignin polymer via enzymes such as laccases, peroxidases, or polyphenol oxidases [5]. CAD has been isolated and characterized from a variety of plant species [13-16], and its crystal structure has been published [17]. The crystal structure indicated that AtCAD4 and AtCAD5 share many structural features with the Zn-dependent medium chain reductase superfamily, although the catalytic $\mathrm{Zn}^{2+}$ of both CADs was coordinated to Glu, a

\section{Major substrates for lignifying CADs in plants}

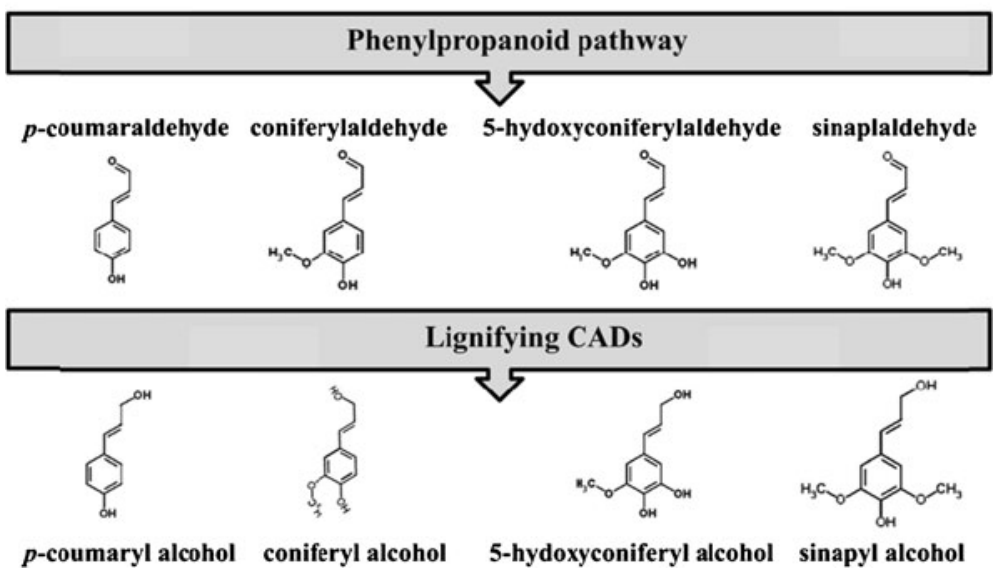

Fig. 1 Major substrates for lignifying CADs in plants. A generalized schematic showing the major aldehyde substrates available for conversion into alcohols (monolignols) by CADs involved in lignification. The ratios and amounts of each substrate and product are plant specific (adapted from Jung et al. [46]) 
motif rarely observed in other eukaryotes. Additional analysis and substrate modeling revealed a binding pocket that contained 12 mostly hydrophobic residues involved in substrate recognition and binding [17]. However, genetic analysis has shown plants contain relatively large $\mathrm{CAD}$ families whose functions are largely unknown but are unlikely to be involved in lignification [18-22]. In other studies [23, 24], domains and specific residues that differentiated between monocot and dicot CADs and bona fide CAD enzymes involved in lignification were identified. The goals of this research were to: (1) identify key protein residues that appear to differentiate lignifying CADs from ones that may have other primary biological roles and (2) establish an initial set of targets for protein engineering efforts towards altering CADs to accept novel substrates that could alter downstream lignin composition. Here, we used the wild type (WT) PviCAD1 enzyme, which is involved in lignification in switchgrass [23], as a template for generating several mutated proteins to understand the roles of specific residues in controlling catalytic rates and substrate preference.

\section{Materials and Methods}

\section{PviCAD1}

PviCAD1 was previously cloned into the pET28a vector (EMD Chemicals, Inc.) using publicly available EST resources as described previously [23]. A list of residues that were selected for site directed mutagenesis is presented in Table 1, along with a brief rationale of why a specific mutation was made. Primers were obtained from Bioneer and MWG Operon, and sequences are provided in Table 2. For site-directed mutagenesis experiments, the reverse primers were the exact complement of the forward primers listed in the table.

\section{Generation of PviCAD1 Mutants}

PviCAD1 mutants were generated using site-directed mutagenesis by generally following the Stratagene's Quick Change site-directed mutagenesis protocol. PviCAD1 in pET28a (EMD Chemicals, Inc.) was used as a template for all reactions except for the double mutant which used H57D as a template. Each PCR reaction consisted of $1 \mu \mathrm{L}$ of each primer, $5 \mu \mathrm{L}$ $10 \times$ reaction buffer, $39 \mu \mathrm{L}$ diethyl pyrocarbonate (DEPC) water, $1 \mu \mathrm{L}$ dNTPs, and $1 \mu \mathrm{L} P f u$ turbo polymerase (Invitrogen Corp.). Reactions were placed in a thermocycler (Biometra T-Gradient, Biomedizinishce Analytik, $\mathrm{GmbH}$ ) and used the following cycling parameters:

Table 1 List of mutations and rationale

\begin{tabular}{ll}
\hline Mutation & Rationale \\
\hline H57D & Mimics D58/57 seen in AtCAD4/5, part of proton shuttling motif \\
L58W & $\begin{array}{l}\text { } 8 \text { L expected to be involved in substrate binding; many CADs of } \\
\text { unknown function have W at equivalent position }\end{array}$ \\
H57D/L58W & Double mutant; DW motif observed in some CADs \\
W119F & Altered residue thought to be important for substrate stabilization; \\
S120T & Mane CADs contain equivalent F at this position \\
D123S & All lignifying CADs have an invariant D; many other CADs contain an equivalent S
\end{tabular}


Table 2 List of primers used for PCR amplifications

\begin{tabular}{ll}
\hline Mutation & Primer sequence \\
\hline H57D & gacatccaccaggccaagaacgacctcggcgcttccaagtacccc \\
L58W & gacatccaccaggccaagaaccactggggcgcttccaagtacccc \\
H57D/L58W & gacatccaccaggccaagaacgactggggcgcttccaagtacccc \\
W119F & gagcagtactgcaacaagaggatcttctcctacaacgacgtcta \\
S120T & cagtactgcaacaagaggatctggacctacaacgacgtctacactg \\
D123S & aggatctggtcctacaactccgtctacactgacggccgg \\
SbCAD6 & \\
Forward & cgctataaagagagaggcaa \\
Reverse & tgatcatttgttgatccaag \\
\hline
\end{tabular}

$95{ }^{\circ} \mathrm{C}(5 \mathrm{~min}), 55^{\circ} \mathrm{C}(3 \mathrm{~min}$.$) , and 72{ }^{\circ} \mathrm{C}(6 \mathrm{~min})$ for 18 cycles. PCR reactions were then

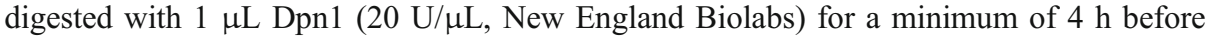
ethanol precipitation to concentrate PCR product. The resulting DNA pellet was taken up in $10 \mu \mathrm{L}$ DEPC water, and 1-7 $\mu \mathrm{L}$ were used in subsequent transformation into NovaBlue (EMD Chemicals, Inc.) or Top10F' (Invitrogen Corp.) cells. For each mutant, several of the resultant colonies were grown up in Luria-Bertani (LB) media, and purified plasmids were sent off for sequence verification. After sequence verification, an appropriate plasmid stock was selected and transformed into Rosetta 2 cells (EMD Chemicals, Inc.) for subsequent protein expression.

\section{SbCAD6 Cloning}

Primers for amplification of SbCAD6 cDNA were designed using MacVector, and the sequences are provided in Table 2. PCR amplification used a cDNA library derived from Sorghum bicolor cv. Atlas. PCR product was verified by restriction digest, gel purified, and cloned into the pET30a vector (EMD Chemicals, Inc.) with another set of primers containing EcoRI and XhoI restriction sites.

\section{Protein Expression and Purification}

All proteins were expressed by growing Rosetta 2 cells in 250 or $400 \mathrm{~mL}$ of LB media to an $\mathrm{OD}_{600}$ of $0.4-0.6$ and adding $0.1 \mathrm{mM}$ isopropyl $\beta$-D-1-thiogalactopyranoside (IPTG). After addition of IPTG, cultures were allowed to grow overnight in an incubator at $18{ }^{\circ} \mathrm{C}$ and shaken at $225 \mathrm{rpm}$. Cells were harvested by centrifugation at 2,800 rpm for $15 \mathrm{~min}$, and pellets were washed twice in $20 \mathrm{~mL} 100 \mathrm{mM}$ Tris-Cl, $\mathrm{pH} \mathrm{7.5,} \mathrm{centrifuged} \mathrm{as} \mathrm{indicated}$ previously, and then taken up in 5-10 mL $100 \mathrm{mM}$ Tris-Cl, pH 7.5, $5 \mathrm{mM}$ dithiothreitol (DTT), and $5 \%$ ethylene glycol. To release soluble protein, $100 \mathrm{mg}$ lysozyme was added to the buffer, and the suspension was sonicated (Branson Digital Sonifier 450) on ice using $10 \mathrm{~s}$ bursts at $30 \%$ amplitude with $30 \mathrm{~s}$ between bursts for $10 \mathrm{~min}$. The suspension was then centrifuged at 2,800 rpm for $15 \mathrm{~min}$ at $4{ }^{\circ} \mathrm{C}$, and supernatant was collected into new $50-\mathrm{mL}$ plastic centrifuge tubes (VWR, Inc.). Protein purification used an AKTA Purifier 900 with a nickel column (GE Healthcare HisTrap FF) that bound the $6 \times$ His-tag on the N-terminus of the protein. The appropriate column fractions were pooled and dialyzed overnight at $4{ }^{\circ} \mathrm{C}$ into $1 \mathrm{~L}$ of $100 \mathrm{mM}$ Tris-HCl, pH 7.5, $5 \mathrm{mM}$ DTT, and $5 \%$ ethylene glycol. Small aliquots $(\sim 150 \mu \mathrm{L})$ of dialyzed protein was placed into $1.7-\mathrm{mL}$ tubes the next morning, flash frozen 
using liquid $\mathrm{N}_{2}$, and stored at $-80{ }^{\circ} \mathrm{C}$ until needed. Protein purity was assessed using SDSPAGE (12\% Bis-Tris Criterion XT, Bio-Rad Laboratories, Inc.) stained with Coomassie Brilliant Blue [25].

\section{Enzyme Assays}

Activity was determined by generally following previously published procedures [13, 23, 24, 26]. Protein activity was tested by monitoring absorbance changes on a BioTek Synergy HT plate reader at $\mathrm{A}_{325}$ (coumaryl aldehyde), $\mathrm{A}_{340}$ (sinapaldehyde and coniferaldehyde), $\mathrm{A}_{290}$ (transcinnamaldehyde), or $\mathrm{A}_{400}$ (coniferyl and coumaryl alcohols). All reactions were carried out in a volume of $200 \mu \mathrm{L}$ and consisted of $100 \mathrm{mM}$ buffer, $200 \mu \mathrm{M}$ cofactor, substrate (1-200 $\mu \mathrm{M}$ depending on the experiment), and $10 \mu \mathrm{L}$ of diluted enzyme. For aldehyde substrates, the buffer was $100 \mathrm{mM}$ MES, pH 6.5, and nicotinamide adenosine dinucleotide phosphate (NADPH) was used as a cofactor; for alcohol substrates, the buffer was $100 \mathrm{mM}$ Tris- $\mathrm{HCl}, \mathrm{pH} \mathrm{8.8,} \mathrm{and} \mathrm{NADP}{ }^{+}$ was used as a cofactor. For each mutant, the appropriate amount of enzyme to use for activity tests was determined by finding a dilution that resulted in a linear change in absorbance over 3 min on $5 \mu \mathrm{M}$ sinapaldehyde. For some of the mutants, higher enzyme amounts had to be used on alcohol substrates due to activity levels that were too low for reliable detection at the initial dilution factor that was determined using sinapaldehyde. During activity tests, enzymes were kept on ice, and new working dilutions were prepared every $10-15 \mathrm{~min}$ in order to minimize the effects of activity loss. Protein concentrations were determined using the Pierce $660 \mathrm{~nm}$ protein assay, and lysozyme was used to generate standard curves.

\section{Computer Modeling}

Protein modeling and visualization was done using PyMOL v. 1.4.1 to visualize the PviCAD1 pdb file. When examining the potential effects of site-directed mutagenesis, residues were mutated in PyMOL, and the most stable side-chain rotamer was used as the basis for structural analysis.

\section{Sequence Alignments and Phylogenetic Trees}

Sequence alignments were made using ClustalW 2.1 [27]. Phylogenetic analysis and the resulting trees were made using tools available at Phylogeny.fr [28]. In both cases, the default program settings were used.

\section{Data Analysis}

Statistical analyses were conducted using PROC GLM in SAS for Windows 9.2 (SAS Institute, Inc., Cary, NC). Nonlinear parameter estimation used routines available in SigmaPlot 11 (Systat Software, Inc., San Jose, CA). Where applicable, standard error propagation techniques were used to propagate error in calculations where two or more variables each had some associated uncertainty that contributed to the final result.

\section{Results}

Velocities for WT and mutant PviCAD1 proteins when tested on a variety of substrates are shown in Fig. 2. WT PviCAD1 displayed the highest velocity when coumaryl and sinapyl 


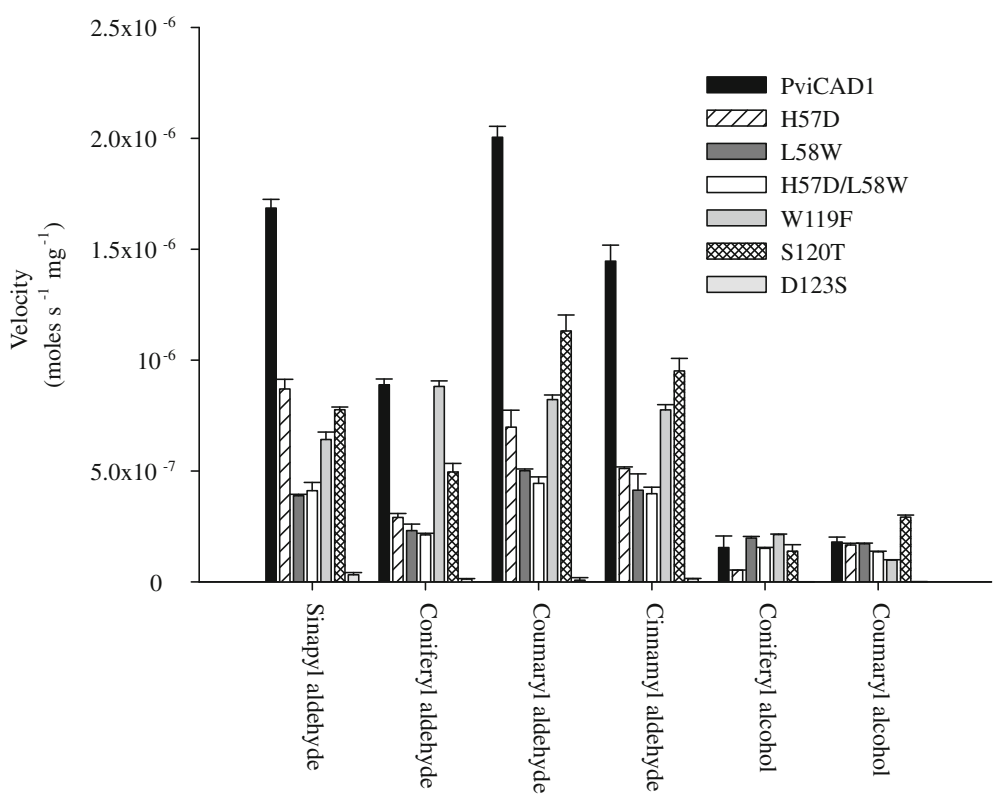

Fig. 2 WT CAD and mutant velocities on different substrates. Activity for each purified protein was monitored on five substrates that had an initial concentration of $100 \mu \mathrm{M}$. Reactions were allowed to proceed for $3 \mathrm{~min}$ and were conducted in quadruplicate. The mean velocity is shown in the graph, and error bars represent the standard deviation

aldehydes were used as substrates $\left(2,000\right.$ and 1,690 nkat $\mathrm{mg}^{-1}$ protein, respectively) and exhibited approximately $\sim 50 \%$ of this velocity on coniferylaldehyde. Both coniferyl and coumaryl alcohols were poor substrates. In single concentration comparative tests and relative to WT catalytic rates, mutant $\mathrm{H} 57 \mathrm{D}$ velocity on sinapaldehyde $(52 \%)$, coniferaldehyde (33\%), coumaryl aldehyde (35\%), trans-cinnamaldehyde (35\%), coumaryl alcohol (92\%), and coniferyl alcohol (34\%) was lower. Mutant L58W velocity was lower on sinapaldehyde (23\%), coniferaldehyde (26\%), coumaryl aldehyde $(25 \%)$, trans-cinnamaldehyde (29\%), and coumaryl alcohol (95\%) and higher on coniferyl alcohol (128\%). The H57D/L58W double mutant velocity showed a similar trend; sinapaldehyde (24\%), coniferaldehyde (24\%), coumaryl aldehyde (22\%), trans-cinnamaldehyde $(27 \%)$, and coumaryl alcohol (75\%) velocities were lower, while coniferyl alcohol velocity (98\%) was nearly identical to WT. The W119F mutation resulted in higher velocity on coniferyl alcohol (138\%) and lower velocities on sinapaldehyde (55\%), coniferaldehyde (87\%), coumaryl aldehyde (41\%), trans-cinnamaldehyde (54\%), and coumaryl alcohol (55\%). The S120T mutant displayed higher activity on coumaryl alcohol (162\%) and lower activities on sinapaldehyde (46\%), coniferaldehyde (56\%), coumaryl aldehyde (56\%), and transcinnamaldehyde (66\%). Mutant D123S displayed sharply reduced activity on all of the tested substrates.

The ratio of enzyme activity against different substrates normalized to its activity on sinapyl aldehyde is shown in Fig. 3. One-way ANOVA and Tukey's pairwise comparison procedure were used to compare the substrate velocities within each CAD. Therefore, the statistical model was designed to analyze velocities of different substrates of each CAD individually rather than across different CADs. Substrate velocity rankings for each protein are provided in Table 3. Overall, WT enzyme displayed an apparent preference for coumaryl 


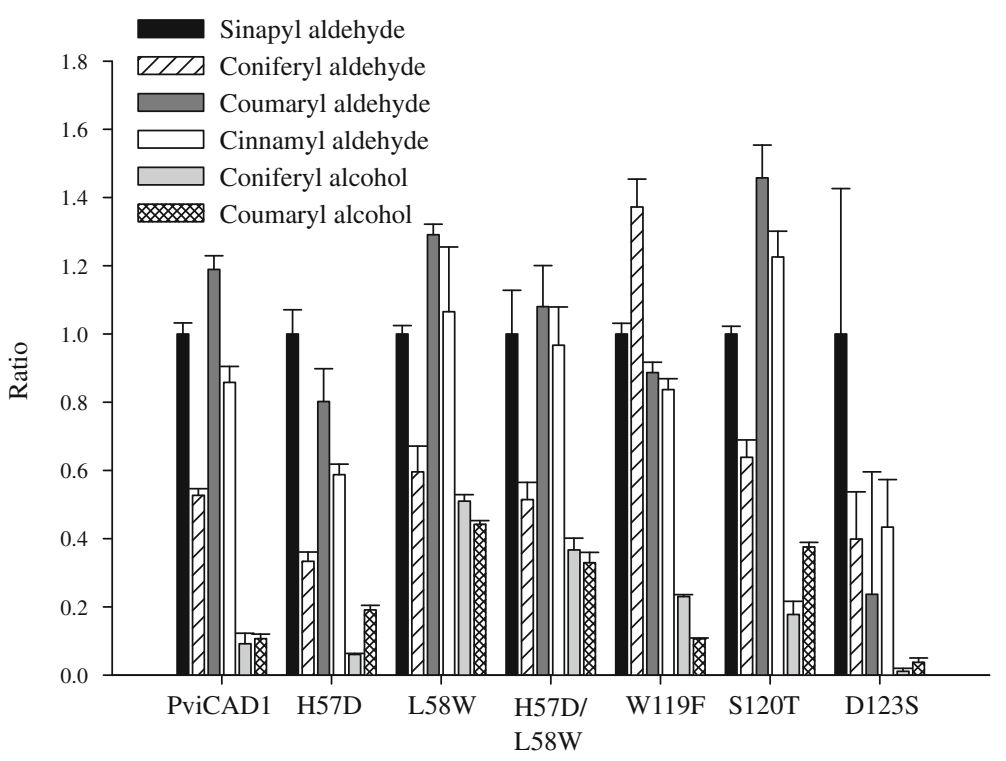

Fig. 3 Velocity results normalized to the sinapaldehyde rate for each enzyme. Velocities for each CAD, when normalized to their respective sinapaldehyde velocity, allowed for better representation of the substrate preferences of each enzyme, although absolute velocity differences between enzymes are subsumed. The error bars represent the standard deviation associated with the calculated ratio and was derived using standard error propagation techniques

aldehyde, while sinapaldehyde and trans-cinnamaldehyde velocities were somewhat lower; all of these aldehydes were strongly preferred over coniferaldehyde. Compared to the WT, velocity rankings for mutant H57D were slightly altered because activity on sinapaldehyde was higher than on all other aldehydes. Mutants L58W and H57D/L58W both showed a preference for coumaryl aldehyde followed by relatively similar velocities on trans-cinnamaldehyde and sinapaldehyde; alcohol velocities were also relatively higher to the aldehyde velocities of these mutants. The $\mathrm{W} 119 \mathrm{~F}$ substrate profile showed a preference for coniferaldehyde over all other aldehydes, and trans-cinnamaldehyde was the least preferred aldehyde which was unique among the tested mutations. The S120T mutation resulted in a protein with a similar substrate profile to WT CAD, although trans-cinnamaldehyde was

Table 3 Ranking of substrate velocities for each mutation

\begin{tabular}{lccccccc}
\hline Substrate & PviCAD1 & H57D & L58W & H57D/L58W & W119F & S120T & D123S \\
\hline Sinapaldehyde & $2 \mathrm{~b}$ & $1 \mathrm{a}$ & $3 \mathrm{~b}$ & $2 \mathrm{a}$ & $4 \mathrm{c}$ & $3 \mathrm{c}$ & $1 \mathrm{a}$ \\
Coniferaldehyde & $4 \mathrm{~d}$ & $4 \mathrm{~d}$ & $4 \mathrm{c}$ & $4 \mathrm{~b}$ & $1 \mathrm{a}$ & $4 \mathrm{~d}$ & $4 \mathrm{~b}$ \\
Coumaryl aldehyde & $1 \mathrm{a}$ & $2 \mathrm{~b}$ & $1 \mathrm{a}$ & $1 \mathrm{a}$ & $2 \mathrm{~b}$ & $1 \mathrm{a}$ & $3 \mathrm{~b}$ \\
trans-Cinnamaldehyde & $3 \mathrm{c}$ & $3 \mathrm{c}$ & $2 \mathrm{~b}$ & $3 \mathrm{a}$ & $3 \mathrm{~b}$ & $2 \mathrm{~b}$ & $2 \mathrm{~b}$ \\
Coniferyl alcohol & $6 \mathrm{e}$ & $6 \mathrm{f}$ & $5 \mathrm{c}$ & $5 \mathrm{c}$ & $5 \mathrm{~d}$ & $6 \mathrm{f}$ & ND \\
Coumaryl alcohol & $5 \mathrm{e}$ & $5 \mathrm{e}$ & $6 \mathrm{c}$ & $6 \mathrm{c}$ & $6 \mathrm{e}$ & $5 \mathrm{e}$ & $5 \mathrm{c}$ \\
\hline
\end{tabular}

Values with the same letter reflect velocities that were not statistically different based on Tukey's HSD test $(\alpha=0.05)$. Comparisons are valid for values compared within each CAD, not across different CADs

$N D$ not detected 
more preferred than sinapaldehyde in the S120T mutant. Large error values for the calculated D123S ratios made determination of preferences among the tested aldehyde substrates difficult to accurately measure, although activity on hydroxycinnamylaldehydes was still higher than on hydroxycinnamyl alcohols. In all cases, CAD velocities for WT or any mutant protein on alcohol substrates were lower than their respective aldehyde velocities; however, for PviCAD1, L58W, and H57D/L58W, the coniferyl alcohol and coumaryl alcohol rates were statistically indistinguishable within each $\mathrm{CAD}$, respectively.

In order to better understand the apparent velocity differences among the engineered CADs, enzyme kinetics were investigated for each CAD on two substrates: sinapaldehyde and coumaryl alcohol. These substrates were chosen because previous work demonstrated that they were suitable reference substrates for switchgrass CAD [23]. In all cases, a Michaelis-Menten kinetic model was fit to the data, and parameter estimates of the kinetic constants $K_{m}, V_{\text {max }}, k_{\text {cat }}$, and $k_{\text {cat }} / K_{m}$ are shown in Table 4 . Relative to the WT protein, for sinapaldehyde, all of the CAD mutants were found to have lower estimated $V_{\max }$ values by at least a factor of 4.8; however, the sinapaldehyde $K_{m}$ values for the H57D and S120T mutants were relatively similar to WT, while the L58W, H57D/L58W, and W119F mutations resulted in much higher $K_{m}$ values for this substrate. Relative to the WT, most of the CAD mutants also had lower $V_{\max }$ values on coumaryl alcohol, with the exception being S120T which had a similar value. Estimated $K_{m}$ values for coumaryl alcohol were low (below $10 \mu \mathrm{M}$ ) for WT PviCAD1 and all of the mutants except for the W119F mutant which had the highest estimated $K_{m}$ of $13.8 \mu \mathrm{M}$ on this substrate.

The D123S mutant exhibited surprisingly low activity on monolignal substrates. Therefore, the PviCAD1 structure was visualized in PyMOL, and Asp123 was changed to a Ser in order to find a potential explanation for this result (Fig. 4). The electrostatic interaction between the Asp123 side chain (partially transparent red bonds) and the Trp119 is characterized by contact distances of $2.9 \AA$ (between Asp123 Od2 and the Trp119 amide N) and $4.3 \AA$ (between Asp123 Od2 and the Trp119 Ne). When the Asp123 side chain is replaced by that of Ser by mutation in PyMOL (opaque red bonds), the rotamer that best accommodates the comparable electrostatic interactions with Trp119 has bond distances of 3.3 and $4.7 \AA$, respectively. Thus, Ser at this position has a diminished capacity for positive electrostatic interactions with Trp119.

Table 4 Parameter estimates for kinetic constants

\begin{tabular}{llllcc}
\hline Protein & Substrate & $V_{\max }\left(\mathrm{mols}^{-1} \mathrm{mg}^{-1}\right)$ & $K_{m}(\mu \mathrm{M})$ & $k_{\text {cat }}\left(\mathrm{s}^{-1}\right)$ & $k_{\text {cat }} / K_{m}\left(\mathrm{~s}^{-1} \mu \mathrm{M}^{-1}\right)$ \\
\hline PviCAD1 & Sinapaldehyde & $2.53 \times 10^{-6} \pm 9.89 \times 10^{-8}$ & $14.5 \pm 1.85$ & 207.3 & 14.30 \\
& Coumaryl alcohol & $3.18 \times 10^{-7} \pm 1.82 \times 10^{-8}$ & $4.2 \pm 1.15$ & 26.03 & 6.20 \\
H57D & Sinapaldehyde & $9.77 \times 10^{-7} \pm 1.56 \times 10^{-8}$ & $12.4 \pm 0.82$ & 80.02 & 6.47 \\
& Coumaryl alcohol & $1.97 \times 10^{-7} \pm 8.04 \times 10^{-9}$ & $7.35 \pm 1.27$ & 16.18 & 2.20 \\
L58W & Sinapaldehyde & $5.23 \times 10^{-7} \pm 3.13 \times 10^{-8}$ & $46.6 \pm 7.7$ & 42.82 & 0.92 \\
& Coumaryl alcohol & $1.88 \times 10^{-7} \pm 5.39 \times 10^{-9}$ & $7.39 \pm 0.90$ & 15.36 & 2.08 \\
H57D/L58W & Sinapaldehyde & $5.56 \times 10^{-7} \pm 3.71 \times 10^{-8}$ & $41.7 \pm 8.0$ & 45.56 & 1.09 \\
& Coumaryl alcohol & $1.53 \times 10^{-7} \pm 4.46 \times 10^{-9}$ & $8.87 \pm 1.04$ & 12.53 & 1.41 \\
W119F & Sinapaldehyde & $1.23 \times 10^{-6} \pm 3.27 \times 10^{-8}$ & $42.3 \pm 3.2$ & 100.5 & 2.38 \\
& Coumaryl alcohol & $1.16 \times 10^{-7} \pm 5.26 \times 10^{-9}$ & $13.8 \pm 2.11$ & 9.52 & 0.69 \\
S120T & Sinapaldehyde & $8.05 \times 10^{-7} \pm 4.37 \times 10^{-8}$ & $14.7 \pm 2.9$ & 65.9 & 4.48 \\
& Coumaryl alcohol & $3.22 \times 10^{-7} \pm 1.41 \times 10^{-8}$ & $7.30 \pm 1.36$ & 26.38 & 3.62
\end{tabular}




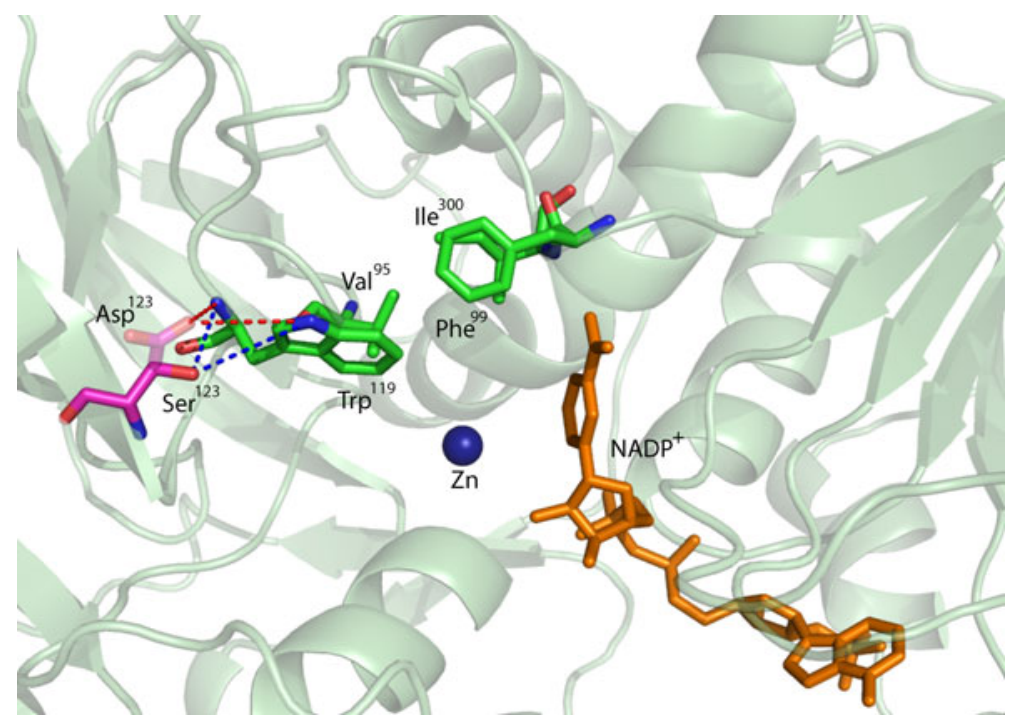

Fig. 4 Molecular model of the CAD-binding pocket. This model shows the potential changes that occurred in the D123S mutant, which resulted in the substantial velocity reduction observed for all tested substrates. Critically, in the D123S mutant, local hydrogen-bonding patterns may have been altered that resulted in a different orientation of Trp119, which appears to be involved in substrate recognition and stabilization

An alignment of selected CAD residues, which was generated using CLUSTAL 2.1, is shown in Fig. 5. The first 13 sequences represent proteins that have been shown to have high activity on monolignol substrates and appear to have roles in lignification. One ancestral CAD from Selaginella also grouped with the lignifying CADs and appeared to share many of their important features. The next 13 sequences consist of CAD-like proteins with generally unknown functions and substrate preferences, which were included to highlight differences between them and lignifying CADs. The residues highlighted in black include most of the AtCAD5 substrate-binding residues that were previously identified by Youn et al. [17]. The sequence alignment indicated that there were clear differences in binding site residues at nearly all positions between the lignifying and nonlignifying CADs.

The conservation of key residues in all bona fide CADs and the enzymatic data obtained from mutational studies described above, which suggested detailed phylogenetic analyses of the CADs and CAD-like proteins as shown in Fig. 5, could yield more insights into the relationships of these proteins and the potential of CAD-like enzymes to participate in lignification reactions. A phylogenetic tree of these proteins is shown in Fig. 6. The CAD and CAD-like sequences analyzed yielded a tree that could easily be distinguished into three clades, namely, lignifying CADs, nonlignifying CADs (almost all the CAD-like sequences analyzed), and an ancestral group containing CAD-like sequences from Selaginella and Physcomitrella. One of the Selaginella sequences (National Center for Biotechnology Information (NCBI) accession number XM_002993954.1) clustered closer to the lignifying CADs and was included in that clade. The lignifying CADs could be further differentiated into the monocot and dicot clades (Fig. 6) that were consistent with earlier published work $[15,18,23,24]$.

We had shown that switchgrass [23] and sorghum [24] contained two and one CADs, respectively, that appeared to be involved in lignification in stems. These species contained additional CAD-like proteins, namely, SbCAD4 from sorghum and PviAroADH from 


\begin{tabular}{|c|c|}
\hline PviCAD1 & YND --276 VV --286 BMVMIGRKSVTGSF! \\
\hline PviCAD2 & YND - -276 VV - -286 PMVMIGRKAVTGSFI \\
\hline LpeCAD1 & YND - - 277 VI - -287 BMVMLGRKTITGSF: \\
\hline TaCAD1 & YND --277 VI $--287 \mathrm{BM}$ \\
\hline OsCAD2 & YND --276 VI --286 \\
\hline BMR6 & YND $--276 \mathrm{VI}--286$ \\
\hline ZmCAD2 & ND $--276 \mathrm{VI}--286$ \\
\hline AtCAD5 & $\mathrm{VD}--276 \mathrm{VI}$ \\
\hline AtCAD4 & ND $--277 \mathrm{VI}$ \\
\hline EgCAD2 & ID $--276 \mathrm{VI}$ \\
\hline PoptrCAD4 & VD $--276 \mathrm{VI}$ \\
\hline PabCAD7 & $\mathrm{ND}--276 \mathrm{VV}$ \\
\hline PtCAD & ND $--276 \mathrm{VV}$ \\
\hline SELMODRAFT187673 & $\mathrm{IND}--276 \mathrm{VV}--286 \mathrm{~F}$ \\
\hline SbCAD6 & ITIKNEWKN --121 IFAYNS --279 LP - -289 FSLVTGGKTLA \\
\hline OsCAD7 & ITIKNEWRN - -132 VFTYNS - -298 LP - - 308 FALVGGGKILAC \\
\hline ZmArOADH & ISIKNEWHN --121 IFTYNS - -279 LP - -289 FDLI IGNKTLA \\
\hline PviAROADH & IFIKNEWNN--124 IFTYNS --282 LP --292 FDLIMGNKTLA \\
\hline SbCAD5 & ASIKNEWGN - -131 IFTYNS - -290 LP - -300 FDLIMGNKTLAC \\
\hline LpCAD2 & LHALKNDWKN - -126 ILTYNS - -284 LP - -294 FALVATNKTLAGSI \\
\hline PtSAD & ASIKNDWGF - -121 ILTYAS - -279 AP - -289 FSLIAGRKIVAGSG \\
\hline PoptrCAD10 & SIKNDWGF - -121 ILTYAS - -279 AP - -289 FSLIAGRKIVAC \\
\hline AtCAD8 & 48 SDLHMVKNEWGM - -117 IQTYGF - -275 AP - -285MPLIFERKMVMGSMI \\
\hline SbCAD4 & 49 TDLHVI KNEWGN - - 118 VLTSNG - -278 AP - -288 YAIITGGKRVAGNGV \\
\hline PviCAD4 & 102 TDLHVIKNYWGS - -171 VLTSNG - -331 VP - -341YAIVPGGKGVAGNS \\
\hline PPATENSXPO & 49 SDLHQIRNEWQN - -118 VWTYNS - -276 MP - -286 VQLVTGRKLVAC \\
\hline SELMODRAFT90947 & YYNS --272 LP $--282 C$ \\
\hline
\end{tabular}

Fig. 5 Alignment of selected CAD protein residues. The first 12 sequences are from proteins likely to be involved in monolignol biosynthesis, and many have been shown to have high activity on monolignol substrates. The next 12 sequences are from other CADs that appear less likely to be involved in lignification. The residues highlighted in black are residues that were predicted to be important in AtCAD5 substrate binding by Youn et al. [17]. Other potentially important or distinguishing residues are highlighted in gray. NCBI nucleotide accession numbers for each gene are as follows: PviCAD1 (GU045611.1), PviCAD2 (GU045612.1), SbCAD6 (XM_002447037.1), TaCAD1 (GU563724.1), OsCAD2 (NM_001052667.1), BMR6 (FJ554574.1), ZmCAD2 (NM_001112184.1), AtCAD5 (NM 119587.3), AtCAD4 (NM 112832.3), EgCAD2 (P31655), PoptrCAD4 (XM 002313839.1), PabCAD7 (Q08350), PtaCAD1 (P41637), SELMODRAFT187673 (XM_002993954.1), SbCAD6 (XM_002447037.1), OsCAD7 (NM_001060383.1), ZmAroADH (NM_001154254.1), SbCAD5 (XM_002445169.1), LpCAD2 (AF472592.1), PtSAD (AF273256.1), PoptrCAD10 (XM_002322786.1), AtCAD8 (NM_119960.2), SbCAD4 (XM_002462303.1), PPATENSXP001773475.1 (XM_001773423.1), and SELMODRAFT90947 (XM_002968611.1)

switchgrass, which grouped to the nonlignifying clade (Fig. 6) and, in the case of SbCAD4, exhibited low or negligible activity against monolignol substrates. Here, we tested another sorghum CAD-like protein, SbCAD6, which appears to be the sorghum ortholog of rice flexible culm (FC1) protein. The rice flexible culm mutation was mapped to a CAD-like gene within the rice genome [29]. Plants carrying this mutation showed increased culm flexibility, reduced cell wall thickness, lowered lignin content, and lowered total CAD activity in internode extracts. However, the sequence for this protein did not have the signature residues at equivalent positions, including Gln53, His57 or Asp57, Trp119, Asp123, Val276, Pro287, Leu290, and Phe299, which appear to be invariant in biochemically characterized lignifying CADs (Fig. 5). The recombinant SbCAD6 protein was analyzed for enzymatic activity. On all of the tested substrates, SbCAD6 velocity was markedly lower when compared to the velocity of the switchgrass WT protein (Fig. 7).

\section{Discussion}

For biochemically based conversion platforms, development of feedstocks that have high conversion efficiency into renewable fuels and chemicals is an important goal. Lignin 


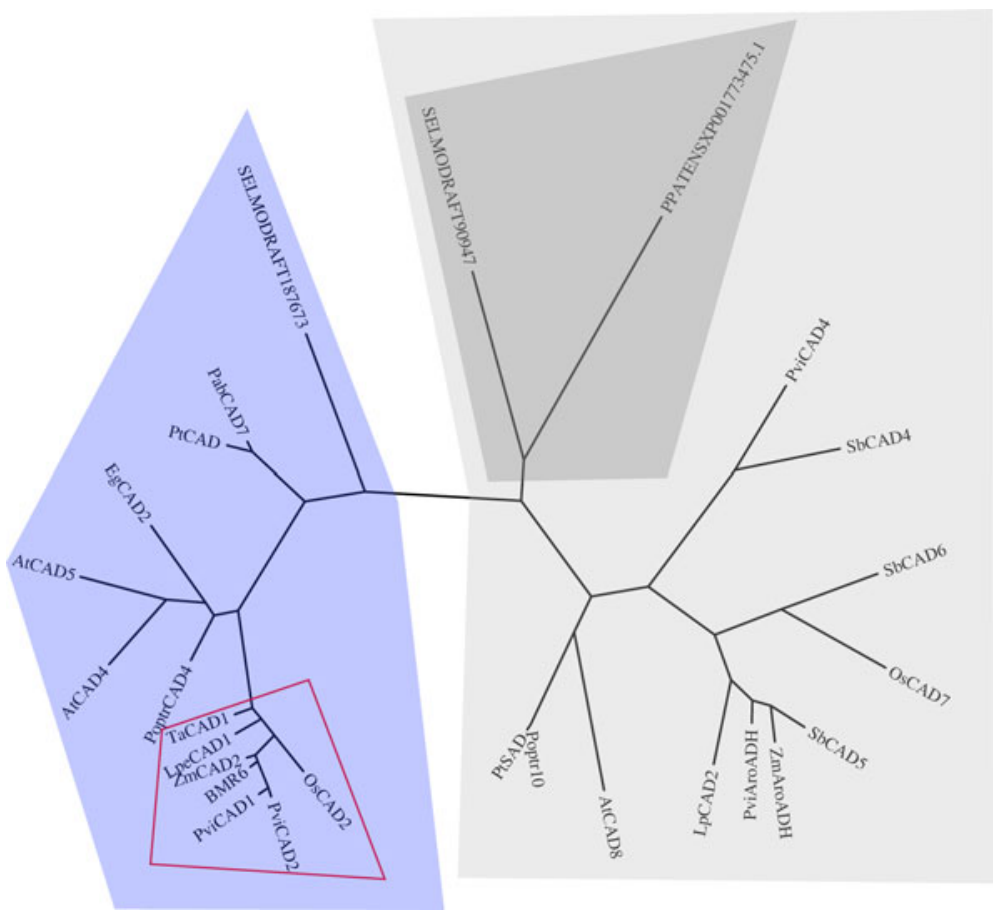

Fig. 6 Phylogenetic tree of CAD protein sequences. The sequences used here are the full sequences of the CADs used in the partial sequence alignment shown in Fig. 4. Sequence grouping: blue polygon=lignifying $\mathrm{CADs}$, light gray polygon=nonlignifying CADs, dark gray polygon=ancestral CADs, and red polygon= monocot CADs

content remains an important bottleneck for biochemical conversion into liquid fuels [30], and lignin reduction or alteration has been shown to improve liquid fuel yields [31, 32]. Considerable efforts are being devoted towards understanding how plants construct and maintain their cell walls for selecting targets for future manipulation using both conventional breeding and genetic engineering strategies that have a goal of producing plants with cell walls that are easier to convert into liquid fuels, such as ethanol. Lignin biosynthesis, including the relevant CADs, represents one such target, although the role(s) of the many other plant CAD-like proteins is unclear. Previous work on switchgrass indicated that it contained two bona fide CADs involved in monolignol biosynthesis [23, 33]. This finding was in agreement with other work that has demonstrated that one or a very limited number of CAD genes have a primary physiological role in cell wall lignification. For instance, in sorghum, a mutation in SbCAD2 was found to be responsible for a brown midrib phenotype $[21,24]$, while in Arabidopsis, only two CADs had meaningful activity against 4hydroxycinnamylaldehyde substrates, and the same two CADs were critical for maintaining suitable stem lignin levels [20,34]. In other plants, CAD disruption has led to one or more of the following: altered phenotypes, altered levels of cell wall solubles, altered lignin content or composition, and/or higher digestibility or saccharification efficiency [35-38]. Transgenic work in monocots has demonstrated that CAD downregulation resulted in lower (Klason) lignin levels and higher IVDMD in tall fescue [39] and lowered total lignin levels and improvements in saccharification efficiency in switchgrass, although no red coloration of plant tissue was noted [33, 40]. Understanding the biological function(s) and specific 


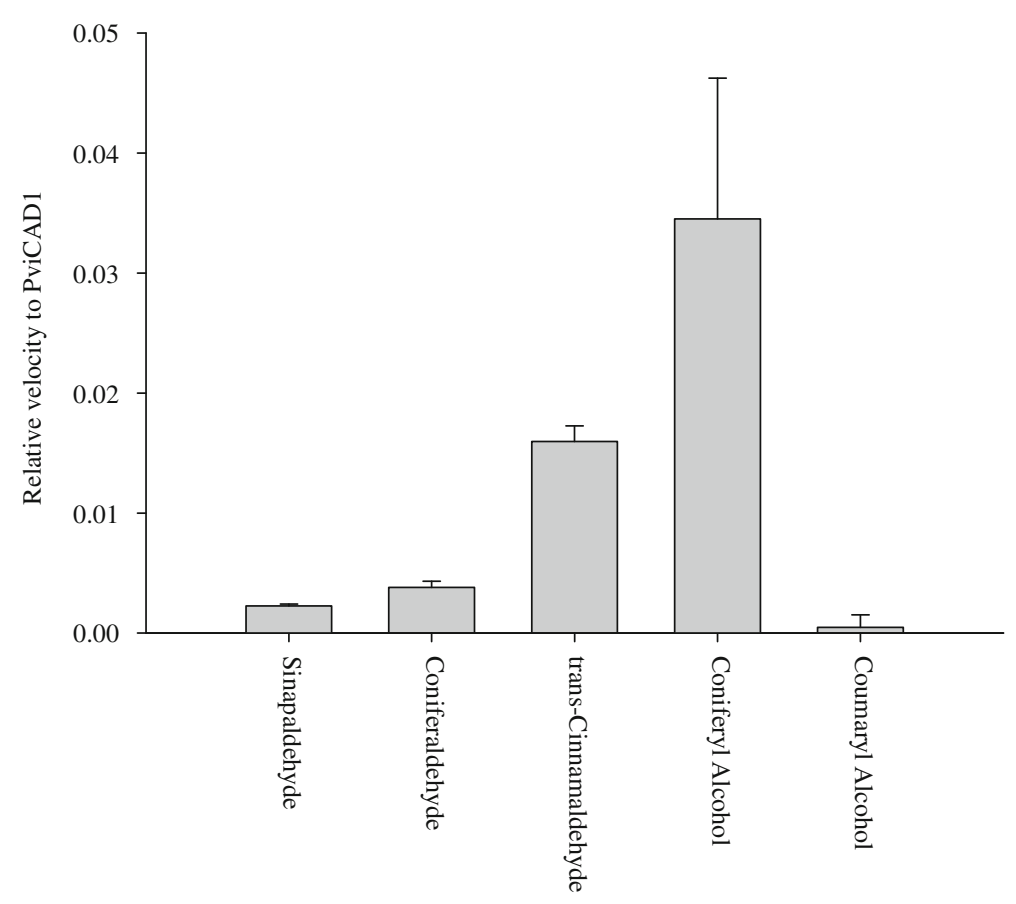

Fig. 7 Activity of SbCAD6 on several different substrates. The displayed values represent the ratio of SbCAD6 velocity to WT PviCAD1 velocity on the same substrate. Substrate concentration was $100 \mu \mathrm{M}$. Error bars represent the standard deviation

residues that govern substrate specificity, particularly of the CADs that are involved in cell wall lignification, is an important part of overall efforts towards understanding cell wall synthesis and potential manipulation for easier deconstruction of plants for renewable fuels and chemicals [41, 42].

The crystal structure of a dicot CAD, AtCAD5 [17], revealed a binding site that consisted of 12 residues: Thr49, Gln53, Leu58, Met60, Cys95, Trp119, Val276, Pro286, Met289, Leu 290, Phe299, and Ile300. Additionally, Youn et al. [17] proposed a proton shuttling mechanism that included Thr49, His52, and Asp57. In at least some monocots, this shuttling mechanism has been shown to apparently use His57 rather than Asp57 [23, 24]. An earlier model of Eucalyptus gunnii CAD2, based on the structure of horse liver alcohol dehydrogenase, suggested that Phe299 and Trp119 were important for stabilizing the phenolic ring of hydroxycinnamylaldehyde substrates [43]. Additionally, Cys95 in AtCAD5, which corresponds to Va196 in AtCAD4, Ile95 in EgCAD2, and Va195 in PviCAD1, was suggested to also be involved in determining substrate specificity [17].

Earlier site-directed mutagenesis of CADs showed the importance of Ser212 in cofactor binding [44] and Glu70 as a critical residue for coordination of the catalytic zinc residue [17]. In this study, residues were specifically chosen that either mimicked the corresponding residues in apparent nonlignifying CADs or changed the characteristics of the substratebinding pocket (see Table 1). Two of the most conservative mutations H57D and S120T had relatively modest effects on activity. Changing His57 to Asp resulted in lower velocities on all tested substrates except coumaryl alcohol, although preference for coumaryl aldehyde appeared to be reduced in the H57D mutant and enhanced in the S120T mutant. Dicots 
generally appear to use an Asp for proton shuttling at position 57, while many monocots seem to use His for this purpose. The H57D results may thus be a reflection of structural optimization in PviCAD1 and other monocot lignifying CADs for use of His rather than Asp. The other highly conservative mutation, S120T, was chosen because our analysis revealed that all known bona fide CADs with a primary physiological role in lignification contain Ser at this position, while many other CADs have an equivalent Thr. This division was also apparent in previous analysis of plant-specific CAD families in Arabidopsis and sorghum [20, 21]. Changing Ser120 to Thr resulted in lower velocities against cinnamylaldehydes when compared to WT, although the reductions for coniferyl, coumaryl, and trans-cinnamylaldehydes were less pronounced than in the H57D mutant. However, S120T apparent efficiency $\left(k_{\text {cat }} / K_{m}\right)$ was still lower than WT on these substrates, which again indicated structural optimization for Ser over Thr.

Three other mutations in the substrate-binding pocket had stronger impacts on velocity and apparent substrate preferences. The first of these, L58W, was chosen because many CADs contain a Trp at this equivalent position, while CADs with confirmed high catalytic rates against monolignal substrates have a nearly invariant Leu (see Fig. 5). This mutation, while not changing polarity within the active site, reduced velocity on all of the aldehyde substrates and sharply increased the sinapaldehyde estimated $K_{m}$, which suggested that the bulky Trp side chain was hindering substrate movement into the binding pocket. Molecular modeling confirmed that this was likely the case as the Trp side chain appeared to protrude into and shrink the overall size of the binding pocket. The reduced binding pocket size also altered apparent substrate preferences since activity on coumaryl aldehyde and trans-cinnamaldehyde was higher than both sinapyl and coniferyl aldehydes. The double mutant, $\mathrm{H} 57 \mathrm{D} / \mathrm{L} 58 \mathrm{~W}$, was created based on the fact that many CADs have an equivalent DW or EW sequence motif at the H57/L58 positions when compared to WT. The double mutant displayed a nearly identical activity and kinetic profile to L58W, which suggested that the Trp was clearly the dominant factor in determining substrate velocities and preferences. Notably, two conifer CAD sequences, PtaCAD [45] and PabCAD7 [46], have a 57EM58 sequence at this position. Because gymnosperm CADs have displayed very low catalytic activity on sinapaldehyde [14, 47], it is possible that the HL or DL motif present in monocot and eudicot CADs may have evolved to increase activity on a range of monolignals, including sinapaldehyde and $p$-coumaryl aldehyde.

The W119F mutation was selected because all known lignifying CADs have a Trp at this position, while the equivalent position appears to be more variable in other CADs. As previously noted, W119 is expected to serve an important role in stabilizing the six-carbon ring structure of hydroxycinnamylaldehyde substrates, and thus, a residue change at this position could alter the overall enzyme activity and substrate preferences. This was indeed the case: the W119F mutation resulted in a protein with generally higher catalytic rates than the other single (H57D) or double (H57D/L58W) active site mutants. Additionally, the W119F mutation had a strong influence on substrate preferences since this change resulted in a protein with a higher velocity on coniferaldehyde than on sinapaldehyde and a clear preference for coniferyl alcohol over coumaryl alcohol, which was unique among the tested CAD mutants. Kinetically, the higher estimated $K_{m}$ values, coupled with lower turnover numbers and lower $k_{\text {cat }} / K_{m}$ values, argue for Trp119, serving an important role in helping to stabilize substrate interactions, which was suggested by earlier CAD structural studies $[17,43]$.

One mutation, D123S, resulted in a protein that was essentially inactive. This was an unexpected finding since Asp123 was not predicted to be involved in substrate binding or catalysis [17]. Therefore, it is apparent that Asp123 is critical to WT activity and, likely, all 
bona fide lignifying CADs since this residue appears to be absolutely conserved among them. Many other CADs have a Ser at this equivalent position, which may be equally important for maintaining native activity, although other residues, including Gly and Phe, were also present in some CADs at this site. In an analysis of sorghum CADs, SbCAD7 and SbCAD5 contained Ser at this equivalent site, while other CAD family members contained Gly [21], which was in agreement with the results obtained here. Molecular modeling suggested that localized hydrogen-bonding patterns were altered in the D123S mutant. This change in hydrogen bonding may have resulted in a localized conformational change that prevented Trp119 from serving its important substrate stabilizing function through aromatic stacking interactions, resulting in the observed dramatically lower activity rates. A crystal structure of this mutant is needed, though, to confirm this hypothesis.

The biochemical results with the sorghum ortholog to rice FC1 confirmed the phylogenetic analysis of lignifying CADs and the mutation work reported here (Fig. 6 and [23, 24]). Our results would suggest that CADs with sequence similarities to rice FC1 or sorghum SbCAD6 are unlikely to utilize monolignals as effective substrates. The significant divergence in amino acid sequences between the lignifying CADs relative to rice FC1 would suggest that key amino acid substitutions, along the entire length of protein, would be needed to convert such CAD orthologs into enzymes that could efficiently convert monolignals into monolignols. Since Li et al. [29] did not biochemically characterize the rice protein, it is unclear if this rice CAD-like protein might exhibit different substrate specificities than its sorghum ortholog. Overall, the data presented here underscore the changes in amino acid sequence that has occurred in the bona fide lignifying CADs as compared to the other CADs and CAD-like genes present in most plant genomes. It also suggests that it should be possible to rapidly identify the potential lignifying CADs in as yet unexplored plant genomes. Future engineering of CADs to potentially accept novel lignin monomers would need to consider changes to the binding pocket that maintain key residues, such as W119 and D123, in an optimal position for substrate binding, while assuring efficient transfer of electrons through proton shuttling from NADPH.

Acknowledgments We thank Nathan Palmer for his excellent technical assistance. This work was supported by the USDA-ARS CRIS project 5440-21000-028-00D and in part by the Office of Science (BER), US Department of Energy grant number (DE-AI02-09ER64829). The US Department of Agriculture, Agricultural Research Service, is an equal opportunity/affirmative action employer, and all agency services are available without discrimination. Mention of commercial products and organizations in this manuscript is solely to provide specific information. It does not constitute endorsement by USDA-ARS over other products and organizations not mentioned.

\section{References}

1. Field, C. B., Behrenfeld, M. J., Randerson, J. T., \& Falkowski, P. (1998). Science, 281, 237-240.

2. Delmer, D. P., \& Amor, Y. (1995). Plant Cell, 7, 987-1000.

3. Somerville, C. (2006). Annual Review of Cell and Developmental Biology, 22, 53-78.

4. Pauly, M., \& Keegstra, K. (2008). Plant Journal, 54, 559-568.

5. Boerjan, W., Ralph, J., \& Baucher, M. (2003). Annual Review of Plant Biology, 54, 519-546.

6. Chapple, C., Ladisch, M., \& Meilan, R. (2007). Nature Biotechnology, 25, 746-748.

7. Sarath, G., Mitchell, R. B., Sattler, S. E., Funnell, D., Pedersen, J. F., Graybosch, R. A., \& Vogel, K. P. (2008). Journal of Industrial Microbiology \& Biotechnology, 35, 343-354.

8. Li, X., Weng, J. K., \& Chapple, C. (2008). Plant Journal, 54, 569-581.

9. Dixon, R. A., Chen, F., Guo, D. J., \& Parvathi, K. (2001). Phytochemistry, 57, 1069-1084.

10. Vogel, J. (2008). Current Opinion in Plant Biology, 11, 301-307.

11. Boudet, A. M., Lapierre, C., \& Grimapettenati, J. (1995). New Phytologist, 129, 203-236. 
12. Hisano, H., Nandakumar, R., \& Wang, Z. Y. (2009). In Vitro Cellular \& Developmental Biology - Plant, $45,306-313$.

13. Hawkins, S. W., \& Boudet, A. M. (1994). Plant Physiology, 104, 75-84.

14. Luderitz, T., \& Grisebach, H. (1981). European Journal of Biochemistry, 119, 115-124.

15. Ma, Q. H. (2010). Journal of Experimental Botany, 61, 2735-2744.

16. McAlister, F. M., Lewis-Henderson, W. R., Jenkins, C. L. D., \& Watson, J. M. (2001). Australian Journal of Plant Physiology, 28, 1085-1094.

17. Youn, B., Camacho, R., Moinuddin, S. G. A., Lee, C., Davin, L. B., Lewis, N. G., \& Kang, C. H. (2006). Organic \& Biomolecular Chemistry, 4, 1687-1697.

18. Barakat, A., Bagniewska-Zadworna, A., Choi, A., Plakkat, U., DiLoreto, D. S., Yellanki, P., \& Carlson, J. E. (2009). BMC Plant Biology, 9, 26.

19. Costa, M. A., Collins, R. E., Anterola, A. M., Cochrane, F. C., Davin, L. B., \& Lewis, N. G. (2003). Phytochemistry, 64, 1097-1112.

20. Kim, S.-J., Kim, M.-R., Bedgar, D. L., Moinuddin, S. G. A., Cardenas, C. L., Davin, L. B., Kang, C., \& Lewis, N. G. (2004). Proceedings of the National Academy of Sciences of the United States of America, $101,1455-1460$.

21. Saballos, A., Ejeta, G., Sanchez, E., Kang, C., \& Vermerris, W. (2009). Genetics, 181, $783-795$.

22. Tobias, C. M., \& Chow, E. K. (2005). Planta, 220, 678-688.

23. Saathoff, A. J., Tobias, C. M., Sattler, S. E., Haas, E. J., Twigg, P., \& Sarath, G. (2011). BioEnergy Research, 4, 120-133.

24. Sattler, S. E., Saathoff, A. J., Haas, E. J., Palmer, N. A., Funnell-Harris, D. L., Sarath, G., \& Pedersen, J. F. (2009). Plant Physiology, 150, 584-595.

25. Laemmli, U. K. (1970). Nature, 227, 680-685.

26. Mansell, R. L., Gross, G. G., Stockigt, J., Franke, H., \& Zenk, M. H. (1974). Phytochemistry, 13, $2427-2435$.

27. Chenna, R., Sugawara, H., Koike, T., Lopez, R., Gibson, T. J., Higgins, D. G., \& Thompson, J. D. (2003). Nucleic Acids Research, 31, 3497-3500.

28. Dereeper, A., Guignon, V., Blanc, G., Audic, S., Buffet, S., Chevenet, F., Dufayard, J. F., Guindon, S., Lefort, V., Lescot, M., Claverie, J. M., \& Gascuel, O. (2008). Nucleic Acids Research, 36, W465-W469.

29. Li, X. J., Yang, Y., Yao, J. L., Chen, G. X., Li, X. H., Zhang, Q. F., \& Wu, C. Y. (2009). Plant Molecular Biology, 69, 685-697.

30. Carroll, A., \& Somerville, C. (2009). Annual Review of Plant Biology, 60, 165-182.

31. Dien, B., Sarath, G., Pedersen, J., Sattler, S., Chen, H., Funnell-Harris, D., Nichols, N., \& Cotta, M. (2009). BioEnergy Research, 2, 153-164.

32. Chen, F., \& Dixon, R. A. (2007). Nature Biotechnology, 25, 759-761.

33. Saathoff, A. J., Sarath, G., Chow, E. K., Dien, B. S. and Tobias, C. M. (2011). PLoS One, 6.

34. Sibout, R., Eudes, A., Mouille, G., Pollet, B., Lapierre, C., Jouanin, L., \& Seguin, A. (2005). Plant Cell, 17, 2059-2076.

35. Baucher, M., Bernard-Vailhe, M. A., Chabbert, B., Besle, J. M., Opsomer, C., Van Montagu, M., \& Botterman, J. (1999). Plant Molecular Biology, 39, 437-447.

36. Baucher, M., Chabbert, B., Pilate, G., VanDoorsselaere, J., Tollier, M. T., PetitConil, M., Cornu, D., Monties, B., VanMontagu, M., Inze, D., Jouanin, L., \& Boerjan, W. (1996). Plant Physiology, 112, 1479-1490.

37. Halpin, C., Knight, M. E., Foxon, G. A., Campbell, M. M., Boudet, A. M., Boon, J. J., Chabbert, B., Tollier, M. T., \& Schuch, W. (1994). Plant Journal, 6, 339-350.

38. Jackson, L. A., Shadle, G. L., Zhou, R., Nakashima, J., Chen, F., \& Dixon, R. A. (2008). BioEnergy Research, 1, 180-192.

39. Chen, L., Auh, C.-K., Dowling, P., Bell, J., Chen, F., Hopkins, A., Dixon, R. A., \& Wang, Z.-Y. (2003). Plant Biotechnology Journal, 1, 437-449.

40. Fu, C. X., Xiao, X. R., Xi, Y. J., Ge, Y. X., Chen, F., Bouton, J., Dixon, R. A., \& Wang, Z. Y. (2011). BioEnergy Research, 4, 153-164.

41. Grabber, J. H., Schatz, P. F., Kim, H., Lu, F. C., \& Ralph, J. (2010). BMC Plant Biology, 10, 13.

42. Vanholme, R., Morreel, K., Ralph, J., \& Boerjan, W. (2008). Current Opinion in Plant Biology, 11, $278-285$.

43. McKie, J. H., Jaouhari, R., Douglas, K. T., Goffner, D., Feuillet, C., Grimapettenati, J., Boudet, A. M., Baltas, M., \& Gorrichon, L. (1993). Biochimica Et Biophysica Acta, 1202, 61-69.

44. Lauvergeat, V., Kennedy, K., Feuillet, C., Mckie, J. H., Gorrichon, L., Baltas, M., Boudet, A. M., Grimapettenati, J., \& Douglas, K. T. (1995). Biochemistry, 34, 12426-12434.

45. MacKay, J. J., Liu, W. W., Whetten, R., Sederoff, R. R., \& Omalley, D. M. (1995). Molecular \& General Genetics, 247, 537-545.

46. Schubert, R., Sperisen, C., Muller-Starck, G., La Scala, S., Ernst, D., Sandermann, H., \& Hager, K. P. (1998). Trees-Structure and Function, 12, 453-463.

47. Kutsuki, H., Shimada, M., \& Higuchi, T. (1982). Phytochemistry, 21, 19-23. 